\title{
Perbandingan Bobot Akhir, Bobot Karkas dan Persentase Karkas Berbagai Strain Broiler
}

\author{
Dede Risnajati \\ Jurusan Produksi Ternak Fakultas Pertanian Universitas Bandung Raya \\ Jl. Banten No.11 Bandung 40272 \\ Email:widjajanilawati@yahoo.com
}

\begin{abstract}
ABSTRAK
Penelitian bertujuan untuk mengetahui perbandingan bobot akhir,bobot karkas, dan persentase karkas dari berbagai strain broiler serta mengetahui strain broiler yang menunjukkan bobot akhir, bobot karkas dan persentase karkas paling tinggi. Penelitian dilakukan dengan metode eksperimen. Pola rancangan didasarkan pada Rancangan Acak Lengkap. Sampel broiler berumur 5 minggu yang terdiri dari 3 macam strain (Hybro, Cobb, Hubbard). Setiap sampel strain diulang sebanyak 9 kali. Peubah yang diamati adalah bobotakhir, bobot karkas, dan persentase karkas. Data yang diperoleh dianalisis menggunakan sidik ragam. Dari hasil percobaan dan pembahasan diperoleh kesimpulan strain memberikan pengaruh yang tidak bermakna terhadap bobotakhir, bobot karkas, dan persentase karkas broiler.
\end{abstract}

Kata kunci : broiler, strain, bobot akhir, bobot karkas

\section{Comparison of Final Weight, Carcass Weight and Carcass Percentage of Some Broiler Strains}

\begin{abstract}
The objective of the research was to comperative the final weight, carcass weight and carcass percentages of some broiler strains and and to know the strain that produced the highest final weight, carcass weight and percetage. The research method was survey with design based on Completely Randomized Design. The three strains of broilers were Hybro, Cobb and Hubbard. At 5 weeks old, the chicken were picked up from broiler farms which had the same management. Each was replicated 9 times. Parameters observed were final and carcass weight and carcass percentage. Collected data were analyzed by analysis of variance. The observed strains had no significant difference on final weight, carcass weight and carcass percetages.
\end{abstract}

Key words : broiler, strain, final weight, carcass weight 


\section{PENDAHULUAN}

Broiler merupakan salah satu ternak alternatif untuk memenuhi permintaan masyarakat akan daging dan telah banyak diusahakan baik dalam skala kecil maupun besar. Broiler memiliki karakteristik dengan ciri khas pertumbuhan cepat, efesiensi dalam penggunaan ransum, masa panen pendek, menghasilkan daging berserat lunak, timbunan daging baik, serta kulit yang licin.

Usaha untuk meningkatkan mutu genetik broiler telah banyak dilakukan oleh parapengusaha pembibitan dalam kurun waktu yang cukup lama. Tujuan dari peningkatan mutugenetik tersebut untuk memperbaiki penampilan broiler, dicirikan dengan laju pertumbuhan yang semakin cepat sehingga lebih efisien dalam waktu pemeliharaan dan penggunaan ransum. Usaha tersebut ditempuh dengan cara melakukan persilangan - persilangan antarbangsa ternak maupun antar galur dalam satu bangsa, yang hasilnya dinamakan strain.

Dari tahun ke tahun usaha pembibitan ayam semakin banyak, sehingga strain yang ada di pasaran semakin beragam. Perbedaan mutu genetik yang terdapat pada masing masing strain menyebabkan adanya perbedaan kemampuan dalam merespon lingkungan sehingga terdapat perbedaan dalam kecepatan pertumbuhan. Dengan demikian, bobot akhir yang dicapai pada umur yang sama akan berbeda.

Beragamnya strain yang ada di pasaran memberi peluang kepada peternak untuk memilih strain apa yang akan dipelihara sesuai kondisi lingkungan tempat pemeliharaan agar menghasilkan produksi yang optimal. Ada 3 macam strain yang dipelihara oleh peternak broiler di Kecamatan Geger bitung, Kabupaten Sukabumi, yaitu strain Cobb, Hybro, dan Hubbard. Dari 3 strain tersebut sampai saat ini belum diketahui strain mana yang sesuai dengan kondisi daerah tersebut sehingga menghasilkan bobot badan dan bobot karkas yang paling tinggi. Sehubungan dengan itu, penulis tertarik untuk mengadakan penelitian mengenai perbandingan bobot akhir, bobot karkas, dan persentase karkas berbagai strain broiler.

\section{MATERI DAN METODE}

Sampel terdiri dari 3 macam strain broiler (Hybro, Cobb, Hubbard) umur 5 minggu diperoleh dari peternak di Desa Gegerbitung, Kecamatan Gegerbitung, Kabupaten Sukabumi, yang memiliki kondisi pemeliharaan yang sama. Sampel untuk masing - masing sebanyak 9 ekor, total sampel yang digunakan adalah 27 ekor.

Alat percobaan yang digunakan adalah timbangan analitik dengan kapasitas 200 gram, pisau, kompor dan panci, ember plastik, dan baki plastik. Pelaksanaan prosesing karkas dan tahapan penanganannya mengacu pada Suparno (1992). Data yang dihimpun adalah bobot akhir, bobot karkas, dan persentase karkas. Rancangan percobaan yang digunakan adalah Rancangan Acak Lengkap, data yang diperoleh dianalisis ragam menurut petunjuk Gaspersz (1991).

\section{HASIL DAN PEMBAHASAN}

Rataan bobot akhir, bobot karkas dan persentase karkas strain broiler yang diteliti disajikan pada Tabel 1.

Rataan bobot akhir tertinggi diperoleh dari strain Hubbard sebesar 1976 gram, diikuti strain Cobb sebesar 1970 gram, dan terendah strain Hybrosebesar 1898 gram. Hasil ini sejalan dengan penelitian Terix (1984) dan Annisa (2003) bahwa strain Hubbard, bobot akhirnya lebih tinggi dibandingkan strain lain. North (1984) berpendapat bahwa bobot hidup yang dicapai pada umur yang sama antara berbagai strain akan berbeda dan hal ini disebabkan selain adanya perbedaan mutu genetik juga disebabkan oleh faktorlingkungan yang mendukung potensi genetik tersebut. Dari hasil analisis ragam, diketahuibahwa perlakuan berpengaruh tidak nyata terhadap bobot akhir. 
Tabel 1. Rataan bobot akhir, bobot karkas dan persentase karkas strain broiler yang diteliti

\begin{tabular}{lccc}
\hline \multirow{2}{*}{ Variabel } & \multicolumn{3}{c}{ Strain } \\
\cline { 2 - 4 } & Cobb & Hubbard & Hybro \\
\hline Bobot akhir (g) & 1.970 & 1.976 & 1.898 \\
Bobot karkas (g) & 1.363 & 1.348 & 1.308 \\
Persentase karkas (\%) & 69,16 & 68,25 & 68,69 \\
\hline
\end{tabular}

Pertumbuhan seekor ternak merupakan interaksi antara faktor genetik dan lingkungan (Suharsino, 1976). Menurut North (1984), sumbangan faktor genetik terhadap pertumbuhan lebih kecil daripada faktor lingkungan, artinya faktor lingkungan lebih dominan pengaruhnya terhadap pertumbuhan. Oleh karena itu, hasil yang diperoleh menunjukkan strain berpengaruh tidak nyata terhadap bobo takhir.

Rataan bobot karkas tertinggi diperoleh dari strain Cobb sebesar 1.363 gram, diikuti strain Hubbard sebesar 1.348 gram, dan terendah strain Hybrosebesar 1.308 gram meskipun bobot akhir strain Hubbard lebih tinggi dari strain Cobb, namunbobot karkasnya ternyata strain Cobb lebih tinggi dari strain Hubbard. Hal ini kemungkinandisebabkan bagian - bagian yang dibuang yaitu kepala, kaki, bulu, darah, dan jeroan dari strain Hubbard lebih tinggi dibandingkan strain Cobb. Perbedaan mutugenetik menyebabkanperbedaan komformasi tubuh ternak. Haysedan Marion (1973) menyatakan bobot karkas yang dihasilkan dipengaruhi oleh beberapa faktor yaitu umur, jenis kelamin, bobot potong, besar dan komformasi tubuh, perlemakan, kualitas dan kuantitas ransum serta strain yang dipelihara.

Berdasarkan hasil analisis ragam, diketahui perlakuan berpengaruh tidak nyata. Perlakuan yang berpengaruh tidak nyata terhadap bobot akhir akan demikian pula pengaruhnya terhadap bobot karkas. Menurut Resnawati dan Hardjoworo (1976), bobot karkas secara langsung berhubungan dengan bobot hidup.

Rataan persentase karkas tertinggi diperoleh dari strain Cobb sebesar 69,16\%, diikuti strain Hybro sebesar 68,69 \%, dan terendah strain Hubbard sebesar 68,25 \%.
Persentase karkas dari ketiga strain berada pada kisaran angka yang direkomendasikan Rasyaf (1995) bahwa persentase karkas broiler umur 5 - 6 minggu adalah $65-70 \%$ dari bobot akhir. Persentase karkas strain Hubbard paling rendah dibandingkan strain Copp dan Hybro. Hal ini disebabkan pada karkas strain Hubbard terdapat banyak lemak. Menurut Mountney (1976), lemak danjeroan merupakan hasil ikutan yang tidak dihitung dalampersentase karkas sehingga jika lemak tinggi maka persentase karkas akan rendah.

Berdasarkan hasil analisis ragam diketahui bahwa perlakuan berpengaruh tidak nyata $(\mathrm{P}>0,05)$ terhadap persentase karkas. Persentase karkas merupakan perbandingan antara bobot karkas dengan bobot akhir. Perlakuan berpengaruh tidak nyata terhadap bobot akhir danbobot karkas sehingga dengan demikian perlakuan berpengaruh tidak nyata pula terhadap persentase karkas.

\section{KESIMPULAN}

Dari hasil analisis dan pembahasan dapat diambil kesimpulan bahwa strain memberikan pengaruh yang tidak bermakna terhadap bobot akhir, bobot karkas, dan persentase karkas broiler.

\section{DAFTAR PUSTAKA}

Annisa, Y., 2003. Pengamatan Performan Beberapa Strain Ayam Broiler di Peternakan Farm Kecamatan Cimaung. Kabupaten Bandung.

Gaspersz, V. 1991. Metode Perancangan Percobaan. Penerbit Armico. Bandung.

Hayse, P.L. and W.W. Merion. 1973. Eviscerated Yield Components Part and 
Meat Skin Bone Ration in Chicken Broiler. Poultry Science 52 ; 718 - 721.

Mountney, G.J. 1976. Poultry Product Technology. $2^{\text {nd }}$ Ed. The Avi Publishing Co. Inc. Westport. Conecticut.

North, M.O. and D.D. Bell. 1990. Commercial Chicken Production Manual. $3^{\text {th }}$. Ed. The Avi Publishing Co. Inc Westport. Conecticut.

Rasyaf, M. 1995. Beternak Ayam Pedaging. Cetakanke - 13.Penebar Swadaya. Jakarta.

Resnawati, H. dan P. Hardjosworo.1976. Pengaruh Umur terhadap Persentase
Karkas danEfisiensi Ekonomis pada Ayam Broiler Unsexed. Lembaran LPP IV.

Suharsono.1976. Respon Broiler terhadap Berbagai Kondisi Lingkungan. Disertasi Fakultas Pasca Sarjana. Universitas Padjadjaran. Bandung.

Therix, J.F.B. 1985. Pengaruh Berbagai Imbangan Lisin dan Energi Dalam Ransum terhadap Performan Beberapa Strain Ayam Broiler Jantan dan Betina. Tesis.Fakultas Pasca Sarjana. Institut Pertanian Bogor. Bogor. 